Volume 9, No.3, May - June 2020

International Journal of Advanced Trends in Computer Science and Engineering

Available Online at http://www.warse.org/IJATCSE/static/pdf/file/ijatcse66932020.pdf

https://doi.org/10.30534/ijatcse/2020/66932020

\title{
Review on the Application of Artificial Neural Networks in Real Estate Valuation
}

\author{
Nkolika J. Peter ${ }^{1}$, Hilary I. Okagbue ${ }^{2}$, Emmanuela C.M. Obasi ${ }^{3}$, Adedotun O. Akinola ${ }^{4}$ \\ ${ }^{1}$ Department of Estate Management, Covenant University, Ota, Nigeria \\ ${ }^{2}$ Department of Mathematics, Covenant University, Ota, Nigeria, "hilary.okagbue@ covenantuniversity.edu.ng \\ ${ }^{3}$ Department of Computer Science and Informatics, Federal University, Otuoke, Nigeria \\ ${ }^{4}$ Department of Architecture, Covenant University, Ota, Nigeria
}

\begin{abstract}
Real estate appraisal is needed in assessment of the value of properties and contribute the regional economy of any country. Real estate valuation is thus an important subject, which has to be studied carefully as there are many individual subjective criteria, which often results in variations, which makes the traditional valuation methods to be inadequate. This work aimed at coping with the complexity of real estate valuation, by putting forth the advantages of artificial neural network, one of the novel model of real estate appraisal. The review of literature has helped to establish that the neural network model is better than the traditional model previously. This work opens up a new and better understanding to the principle of real estate evaluation.
\end{abstract}

Key words: Appraisal, Artificial Neural Networks, price prediction, real estate valuation, risk assessment.

\section{INTRODUCTION}

Real estate remains one of the most viable investment options which is often characterized by high return on investment. The value of money and current state of economy are predictors of the returns accruable from real estate investment. Real estate appraisal is a means of assessing how the aforementioned factors determine the value of real estate in any given country. Rapid urbanization and population growth have helped to increase the use of estate appraisal since it is needed to assess the availability, demand and supply of housing to cater the needs of ever increasing population and urbanization. [1]. However, with the emergence and growth of real estate transactions, a series of social contradictions have arisen since real estate valuation reports are used in many areas such as taxation, acquiring loan facility in banks, socialization, buying and selling of properties, amongst others. In all the areas that real estate valuation report is needed, different approaches and estimation of the value are done. For this reason, each application's results show differences according to various studies carried in this aspect [2-3]. This situation is worrisome for the real estate industry. To improve this unfavorable situation, Ibisola, et al. [4] have stated that there is the need to determine real estate values objectively, truly and safely, which is of great importance for social economy.

Currently, the real estate industry is becoming more computerized over the years with many real estate brokers and appraisers developing online services, such as an automated valuation model, to estimate the house price for clients automatically using optimization algorithms or evolutionary computational methods [5-8].

Artificial neural networks (ANN) commonly known as neural networks are computational methods or systems uniquely inspired by the biological networks of brains and the neurons that constitute the nervous system, hence, ANN mostly mimics the human brain. ANN model is designed to perform tasks (computation) by learning from given example without necessarily following specific rules or without specific prior knowledge of the tasks. However, they generate results from the example that they process. ANN is a member of evolutionary computational methods [9].

Artificial neural networks have been used in different fields and areas such as computer vision, pattern recognition (action [10], image [11], speech [12], handwriting [13], number gesture [14], data mining [15], virtualization, machine translation, email spam filtering, social network filtering, cybernetics [16] and medical diagnostics [17] to mention but a few. Various variants and modifications of the method exist and several platforms have been designed for the implementation. Modifications are necessary to improve on the very aspects of ANN. Modification to ensure a faster rate of learning has been reported [18]. Besides, modification has been done to incorporate evolution into the learning method [19]. Moreover, using ANN demands the following.

a). The choice of the model (data structure and application).

b). The relevant learning algorithm, robustness and convergence considerations.

Generally, the major strength of the ANN is in the 
following;

a). Function or fitness approximations and modeling [20].

b). ANN is very robust in handling multimodal and multiobjective constrained optimization problems [21].

c). Classification [22-23].

d). Data processing for example clustering.

e). Robotics for example motion planning.

f). Control [24-25].

Other details of ANN can be obtained in [26-27].

Neural networks are one of the sophisticated machine learning techniques presently attracting attention from scientists, engineers, and statisticians, among others. They have gained popularity in recent years. However, the use of neural networks by architects, builders and valuers in the real estate sector industry and real estate valuation, in particular, does not appear to have gained much popularity.

Real estate valuation or appraisal is the estimation of the value of real estate for the purpose of sales, loan application, investment, listing, taxation and insurance, amongst other purposes. The computation of the value of real estate usually considers different factors. Examples of such factors are physical attributes of the subject property like the fixtures and fittings within the property, neighborhood qualities, socioeconomics, government controls and regulation, which are ultimately, influenced by demand, utility, scarcity and transferability. The valuation report generated from real estate appraisal or valuation is used by businesses, credit agencies, regulatory agencies, government, mortgage, individuals and investors (local and foreign) when making informed decisions regarding real estate transactions. In addition, investment in real estate remains an interesting area that benefits from foreign direct investment (FDI).

Volatility of the variables renders the available models less effective as the uncertainty or changes in the variables present inherent risks of undervaluing or overvaluing of real properties. This is exacerbated by the time value of money. The uniqueness of properties entails deviations from established valuation or appraisal methods. Apart from the time and value of money, the following factors could be culpable;

a). Location: Prices of properties vary significantly from one location to another. Properties located in an affluent neighborhood is very likely to be expensive than those located in slums. Siting of industries, churches and other big establishments in a certain location is most likely to affect the price of properties within such a neighborhood positively. On the other hand, proximity to pollution prone factories, military or nuclear sites, and cemetery can equally affect the value of properties within a certain radius of such site negatively.

b). Purpose or use: Residential buildings are most likely to be less valued than commercial buildings.

c). Government policies: Government decisions can affect the price of properties. Examples include; approval of public or private universities, citing of government agencies, airports, seaports, markets, stadiums and sports facilities.

d). Age and conditions of the buildings. The market value of some property depreciates over time. Depreciation in this aspect can come in form of physical, functional and economic. The most form of physical depreciation is structural defects or problems, which subject the property to the likelihood of collapse.

e). Sale circumstances: The threat of foreclosure is most likely to affect the price of buildings. Also,

f). Physical attributes of the property: These include; size, landscape, number of rooms, ventilation, lighting, quality of construction, floor type, privacy, greenness, interior decoration, heating, cooling, swimming pool, car parking lot, garden, etc. In some cases, weather, security and climate change affects the price of houses.

The aim of this paper is to review different aspects of application of ANN in real estate valuation. It will show that the price estimation or forecasting is not the only use of ANN in this context. The motivation is derived from the result of numerous research activities on the use of ANN in forecasting [28]. The research will present research information to experts in this area.

\section{ARTIFICIAL NEURAL NETWORKS IN REAL ESTATE APPRAISAL}

Researches exploited the computational capacity and robustness of the artificial neural networks and used them in real estate valuation or appraisal. This review has successfully classified the application into three different areas. They are:

a). Estimation of the value of real estate.

b). Price prediction or forecasting of real estate.

c). Other applications as listed in Table 1.

The research articles used for the classification were sourced from different peer-reviewed academic databases.

\section{ESTIMATION OF VALUE OF REAL ESTATE}

This area is further classified into three, namely; evaluation models, mass appraisal, and risk assessment and evaluation. All are different dimensions of real estate valuation and appraisal.

\subsection{Evaluation Models}

Evaluation models are dedicated to estimating the price of real estate properties. Many quantitative and qualitative variables affect the value of an estate. Estate valuers or practitioners using evaluation models routinely do the estimation of the value of an estate. The models capture different quantitative and qualitative variables that affect the value of the given property. This means that multivariate models are preferred in estate appraisal. Regression analysis, time series [29] and quantitative comparative 
approach [30] are some of the available tools used in this aspect. A combination of regression analysis and ANN performed better than the individual models [31]. It has also be shown that some data mining models and evolutionary computational methods have shown to be effective when combined with regression analysis or used in solitude for real estate valuation. These include Support Vector Machine [32], $\mathrm{K}$ nearest neighbor [33], decision tree [34], particle swarm optimization algorithm [35] and genetic algorithm [36]. The precision of the data mining models could be improved by bagging [37] or a combination of bagging and other algorithms [38]. The use of regression analysis or other similar models is plagued with nonlinearity of relationship among the variables, the presence of unnecessary information and the absence of key information that greatly affects the evaluation. Autocorrelation of some variables also presents some challenges during real estate valuation [39]. Hence, ANN tackles the problem, for instance, when it is combined with geographic information system (GIS) [40-41]. Failure to capture the necessary information by the given model impedes the accurate determination of the financial viability of real estate, increases the risk of borrowing and erodes the credibility of real estate valuation [42]. Traditional valuation methods are handicapped in estimation of property value arising from huge (big) data that captures the location, socioeconomic, physical, environmental and demographic characteristics of real estate [43-44]. ANN has shown to be very keen on tackling the problem [45].

The advantage of ANN over the traditional evaluation tools is that the learning function [46] and nonlinear processing ability of ANN can improve the randomness and uncertainty of existing evaluation methods thereby minimizing the likelihood of information loss [47]. Hence, ANN is one of the major evaluation tools that guarantees accurate property value estimation, even though in the presence of large datasets [48].

The application of ANN has been extended to the evaluation of real estate companies in order to determine their competitive advantage, viability and strength [49-50]. The application has been extended to the appraisal and monitoring of real estate market [51]. Government agencies depend on accurate property valuation estimation for computation of property taxes [52].

\subsection{Mass Appraisal}

Conventional evaluation methods cannot be applied in the estimation of prices of large amount of properties. The complexity of the nature of the characteristics underneath the mass houses means that advanced computational methods are needed to create a reasonable evaluation model. Artificial neural networks have been used in this context to estimate values between properties [53]. The big data usually encountered in mass appraisal can be handled by the application of ANN and a combination of other data mining tools such as decision trees, random forest, boosted trees, KNN [54] and others. The application of ANN in the mass appraisal of properties has improved the credibility and efficiency of the evaluation system [55]. Unarguably, this area remains a fertile ground for more research activities as revealed by [56].

\subsection{Risk Assessment and Evaluation}

Apart from the usual valuation of real estate, valuers also determine the risk associated with properties. The risk of the individual variables (components) is assessed to determine the net risk of the property. Risk evaluation is very crucial since real estate carries a lot of risks and adequate knowledge of the risk is essential for investment and business decisions. The level of risk determines the extent of investment. Traditionally, qualitative methods are used in the risk assessment in this context, which is highly subjective and often inaccurate. ANN can be used in this aspect by leveraging on its self-organization and learning capabilities in order to accurately quantify the risk by excluding the subjective factors [57] in real estate [58] and credit risk of real estate in banks [59]. The adoption of ANN in risk assessment ensures credibility and is necessary to avoid waste of scarce resources and foreclosures [60]. In the case of credit risk, ANN helps to determine the state of credit rating and to handle complex relationships that are inbuilt in credit management in banks [61].

ANN and its combination with fuzzy comprehensive evaluation have been used to determine the weight of every risk factor and relate them to the overall risk of the real estate [62]. Risk assessment of contracting in real estate has also been reported [63]. This was done by the use of ANN and SVM. The real estate risk assessment remains an integral part of the general risk assessment of which the ANN has proven to be an efficient tool for estimating the former [64].

\section{PRICE PREDICTION AND FORECASTING OF REAL ESTATE}

Estate valuation is not just limited to valuing or appraising a property, it also predicts the price using historical data on various variables affecting the price or value of the property. The act of prediction involves the extraction of useful information from a given raw data in other to forecast or predict the unknown. Comparisons are subsequently made with the current selling prices. Predictions are often cumbersome using the traditional evaluation methods but the advent of computers and algorithms such as ANN has made it easy to explore the correlations between the variables that affect the price of real estate and create patterns within multi-dimensional variables [65]. Data mining tools are widely used in this aspect [66]. Often, the evaluation models used in real estate appraisal are used in price prediction. As stated earlier, the randomness of the variables reduces the predictive accuracy of evaluation models which 
are mainly modeled as deterministic [67]. The prediction has to be accurate and a pointer to the success or failure of real estate [68]. High positive correlation coefficient is desirable to indicate that the prediction is accurate [69]. Different residential real property variables can be used [70]. Examples are location, prior prices, building conditions, housing area and number of rooms [71], consumer spending [72], value of money [73], demand and supply, government policies, security [74], disposable income and rediscount rate [75].

ANN has been combined with fuzzy methods [76], ordinary least squares regression [77], logistic regression [78], Markov chain [79], support vector regression (SVR) [80], principal components analysis [81], particle swarm optimization (PSO) algorithm [82], decision tree [83], gradient boosting machines [84] and genetic algorithm [85-86] in prediction of price of properties. The unique strength of ANN is that it captures the uncertainties of the variables that constitute the predicting model at a reduced computational time and increased accuracy. Unique cycles or seasonal variations in the price of real estate can be precipitated using the ANN [87]. ANN model help to identify the unique factors that are most likely to affect the price of properties [88]. This helps to facilitate quick decisions by investors, buyers, government and financial institutions.

Table 1: Related areas of Application of ANN in real estate valuation

\begin{tabular}{lc}
\hline & Reference \\
\hline $\begin{array}{l}\text { Image classification of houses } \\
\text { to aid in real estate appraisal }\end{array}$ & {$[95]$} \\
$\begin{array}{l}\text { Identification of opportunities } \\
\text { in real estate market }\end{array}$ & {$[96]$} \\
$\begin{array}{l}\text { Incorporation of energy demand } \\
\text { in real estate valuation }\end{array}$ & {$[97]$} \\
$\begin{array}{l}\text { Image classification of interior } \\
\text { of properties }\end{array}$ & {$[98]$} \\
$\begin{array}{l}\text { Image classification of both } \\
\text { interior and exterior of buildings }\end{array}$ & {$[99]$} \\
$\begin{array}{l}\text { Clustering of fund of real } \\
\text { estate derived via valuation }\end{array}$ & {$[100]$} \\
$\begin{array}{l}\text { Management of real estate } \\
\text { information }\end{array}$ & {$[101]$} \\
$\begin{array}{l}\text { Core competence estimation } \\
\text { of real estate firms }\end{array}$ & {$[102]$} \\
$\begin{array}{l}\text { Core competence estimation } \\
\text { of real estate firms }\end{array}$ & {$[103]$} \\
$\begin{array}{l}\text { Selection of tax check in } \\
\text { real estate firms } \\
\text { Development of decision } \\
\text { support system for evaluation } \\
\text { Auditing of real estate } \\
\text { evaluation process } \\
\text { Real estate problem solving }\end{array}$ & {$[104]$} \\
\hline
\end{tabular}

Comparison of ANN over other methods showed that despite the predictive capability of ANN, some other models performed better than it. SVM performed better than ANN for small training data [89]. A combination of SVR and rough sets yielded better prediction than ANN [90]. Neuro-Fuzzy Inference System (ANFIS), performed better than ANN [91]. On the other, it has been reported that ANN performed better than linear regression and random forest algorithm in real estate price prediction [92].

An emerging trend in this area is the use of virtual characteristics in the prediction of price of properties using ANN. Datasets used here are the photos of the interior and exterior of the property. This approach has also shown to be better in real estate evaluation than other notable offline and online methods [93]. The use of satellite images, street views and the accessibility in real estate price predictions have been reported [94].

\section{OTHER APPLICATIONS}

Researchers have applied ANN to different areas in real estate based on the objectives of their studies. Hence, the application of ANN is restricted to mass appraisal, evaluation, risk assessment and price prediction. The summary of the miscellaneous applications of ANN is presented in Table 1.

\section{CONCLUSION}

In this study, the challenges with real estate evaluation were studied and a real estate evaluation model based on artificial neural networks was put forward. This study proposes the use of ANN for real estate appraisal. It has presented a review of the state of the art view of the depth and breadth of Neural Network optimization in real estate valuation. Other significant conclusions made from the review are summarized as follows: ANN can successfully produce an error-free valuation result. It has the ability to select tax check in real estate firms, as well as help in the development of decision support systems for evaluation and also the auditing of real estate evaluation process, amongst other benefits.

\section{ACKNOWLEDGEMENT}

The research benefited from Covenant University sponsorship.

\section{REFERENCES}

1. Peter, N.J., Fateye, O.B., Oloke, C.O. \& Iyanda P. (2018). Changing urban land use and neighbourhood quality: evidence from Federal Capital Territory 
(FCT), Abuja, Nigeria. International Journal of Civil Engineering \& Technology, 9(11), 23-36.

2. Ayuthaya, N.P. \& Swierczek, F.W. (2014). Factors influencing variation in value and investors confidence. IOSR J. Bus. Manag., 16(5), 41-51. https://doi.org/10.9790/487X-16514151

3. Skitmore, M., Irons, J. \& Armitage, L. (2007) Valuation accuracy and variation: a meta analysis. In Proceedings 13th Pacific Rim Real Estate Society Conference, Fremantle, WA.

4. Ibisola, A.S. Durodola, O.D, Oluwatobi, A.O., Oni, A.S. \& Peter, N.J. (2019). Factors Contributing to the Valuation of Arts and Artifacts in Ogun State, Nigeria. International Journal of Civil Engineering \& Technology, 10(1), 2224-2231.

5. Fan, G.Z., Ong, S.E. \& Koh, H.C. (2006). Determinants of house price: a decision tree approach. Urban Stud., 43(12), 2301-2315

https://doi.org/10.1080/00420980600990928

6. Gao, L., Guo, Z., Zhang, H., Xu, X. \& Shen, H.T. (2017). Video captioning with attention-based LSTM and semantic consistency. IEEE Trans Multimed., 19(9), 2045-2055.

https://doi.org/10.1109/TMM.2017.2729019

7. Demetriou, D. (2017). A spatially based artificial neural network mass valuation model for land consolidation. Environment and Planning B: Urban Analytics and City Science, 44(5), 864-883.

https://doi.org/10.1177/0265813516652115

8. Park, B., \& Bae, J.K. (2015). Using machine learning algorithms for housing price prediction: The case of Fairfax County, Virginia housing data. Expert Systems with Applications, 42(6), 2928-2934.

https://doi.org/10.1016/j.eswa.2014.11.040

9. Okagbue, H.I., Adamu, M.O. \& Anake, T.A. (2019). Differential evolution in wireless communications: A review. International Journal of Online and Biomedical Engineering, 15(11), 29-52.

https://doi.org/10.3991/ijoe.v15i11.10651

10. Ji, S., Xu, W., Yang, M. \& Yu, K. (2013). 3D Convolutional neural networks for human action recognition. IEEE Trans. Pattern Analy. Machine Intel., 35(1), Article number 6165309, 221-231.

11. Egmont-Petersen, M., de Ridder, D. \& Handels, H. (2002). Image processing with neural networks- a review. Pattern Recognition, 35(10), 2279-2301.

12. Bishop, C.M. (1995). Neural networks for pattern recognition. Clarendon Press. ISBN: 978-0198538493.

13. Graves, A., Liwicki, M., Fernandez, S., Bertolami, R., Bunke H. \& Schmidhuber, J. (2009). A novel connectionist system for improved unconstrained handwriting recognition. IEEE Transactions on Pattern Analysis and Machine Intelligence, 31(5), 855-868.

https://doi.org/10.1109/TPAMI.2008.137

14. Africa, A.D.M., Bulda, L.R., Marasigan, M.Z. \& Navarro, I.F. (2019). A study on number gesture recognition using neural network. International Journal of Advanced Trends in Computer Science and Engineering, 8(4), 1076-1082.

https://doi.org/10.30534/ijatcse/2019/14842019

15. Tawarish, M. \& Satyanarayana, K. (2019). A review on pricing prediction on stock market by different techniques in the field of data mining and genetic algorithm. International Journal of Advanced Trends in Computer Science and Engineering, 8(1), 23-26. https://doi.org/10.30534/ijatcse/2019/05812019

16. Tomar, R. \& Awasthi, Y. (2019). Analysis against DDOS flooding attacks in healthcare system using artificial neural network. International Journal of Advanced Trends in Computer Science and Engineering, 8, 405-410.

https://doi.org/10.30534/ijatcse/2019/6481.52019

17. Abbod, M.F. (2007). Application of Artificial intelligence to the management of urological cancer. The Journal of Urology, 178(4), 1150-1156.

18. Huang, G.-B., Zhu, Q.-Y. \& Siew, C.-K. (2006). Extreme learning machine: Theory and applications. Neurocomputing, 70(1-3), 489-501.

19. Yao, X. (1999). Evolving artificial neural networks. Proceedings of the IEEE, 87(9), 1423-1447.

20. Siegelmann, H.T. \& Sontag, E.D. (1994). Analog computation via neural networks. Theoretical Computer Science, 131(2), 331-360. https://doi.org/10.1016/0304-3975(94)90178-3

21. Okagbue, H.I., Adamu, M.O., Anake, T.A. \& Wusu, A.S. (2019). Nature inspired quantile estimates of the Nakagami distribution. Telecommunication Systems, 72(4), 517-541

22. Omogbadegun, Z., Ogundele, I. \& Oladipupo, O. (2019). Applying Neural Network-based approach to Sickle Cell Disease-related pain classification. Journal of Computer Science, 15(6), 861-872.

23. Dudo, R.O., Hart, P.E. \& Stork, D.G. (2001). Pattern classification (2nd Ed.). Wiley. ISBN: 978-0471056690.

24. Abdulkareem, A., Adesanya, A., Popoola, O. \& Awosope, C.O.A. (2019). Predicting insulation thickness in thermoplastic extrusion process in Nigeria cable industries using artificial neural network. Engineering Letters, 27(4), 907-917.

25. Africa, A.D.M., Asuncion, F.X., Tiberio, J.L. \& Munchua, R.M.F.A. (2019). Sensor-based traffic control network with neural network based control system. International Journal of Advanced Trends in Computer Science and Engineering, 8(4), 983-989. https://doi.org/10.30534/ijatcse/2019/01842019

26. Specht, D.F. (1990). Probabilistic neural networks. Neural Networks, 3(1), 109-118.

27. Schmidhuber, J. (2015). Deep Learning in neural networks: An overview. Neural Networks, 61, 85-117. https://doi.org/10.1016/j.neunet.2014.09.003

28. Zhang, G., Patuwo, E.B. \& Hu, M.Y. (1998). Forecasting with artificial neural networks: The state of the art. Int. J. Forecasting, 14(1), 35-62. 
29. Alexandridis, A.K., Karlis, D., Papastamos, D. \& Andritsos, D. (2019). Real Estate valuation and forecasting in non-homogeneous markets: A case study in Greece during the financial crisis. J. Operat. Res. Soc., 70(10), 1769-1783.

30. Yeh, I.-C. \& Hsu, T.-K. (2018). Building real estate valuation models with comparative approach through case-based reasoning. Appl. Soft Comp. J., 65, 260-271.

31. Pagourtzi, E., Metaxiotis, K., Nikolopoulos, K., Giannelos, K., Assimakopoulos, V. \& Assimakopoulos, V. (2007). Real estate valuation with artificial intelligence approaches. Int. J. Intel. Syst. Tech. Appl., 2(1), 50-57. https://doi.org/10.1504/IJISTA.2007.011573

32. Zhou, S.-J., Cao, L.-M. \& Li, Y.-C. (2008). Evaluation model for real estate investment environment based on SVM. Proceedings, Int. Workshop Model. Simul. Opt., WMSO, Art. no: 4756987, pp. 192-195.

33. Lasota, T., Sachnowski, P. \& Trawiński, B. (2009). Comparative analysis of regression tree models for premises valuation using statistica data miner. Lecture Notes in Computer Science, 5796, 776-787. https://doi.org/10.1007/978-3-642-04441-0_68

34. Graczyk, M., Lasota, T. \& Trawiński, B. (2009). Comparative analysis of premises valuation models using KEEL, rapidminer, and WEKA. Lecture Notes in Computer Science, 5796, 800-812.

35. Liu, Y. (2017). A commercial real estate price evaluation model based on GT-BCPSO-BP neural network. Int. J. Appl. Decision Sci., 10(4), 335-346.

36. Sun, Y. (2019). Real estate evaluation model based on genetic algorithm optimized neural network. Data Science Journal, 18(1), Article number 36.

37. Lasota, T., Telec, Z., Trawiński, B. \& Trawiński, K. (2009). Exploration of bagging ensembles comprising genetic fuzzy models to assist with real estate appraisals. Lecture Notes in Comp. Sci., 5788, 554-561.

38. Lasota, T., Telec, Z., Trawiński, B. \& Trawiński, K. (2009). A multi-agent system to assist with real estate appraisals using bagging ensembles. Lecture Notes in Computer Science, 5796, 813-824. https://doi.org/10.1007/978-3-642-04441-0_71

39. You, Q., Pang, R., Cao, L. \& Luo, J. (2017). Image-Based Appraisal of Real Estate Properties. IEEE Trans. Multimedia, 19(12), 2751-2759.

40. García, N., Gámez, M. \& Alfaro, E. (2008). ANN+GIS: An automated system for property valuation. Neurocomputing, 71(4-6), 733-742.

41. Liu, X.-S., Deng, Z. \& Wang, T.-L. (2011). Real estate appraisal system based on GIS and BP neural network. Transactions of Nonferrous Metals Society of China, 21, s626-s630.

https://doi.org/10.1016/S1003-6326(12)61652-5

42. Yu, C.Y., Lam, K.C. \& Runeson, G. (2008). SVM and entropy based decision support system for property valuation. Proc., 11th Eleventh East Asia-Pacific Conf. on Structural Engine. \& Construction.
43. Zhang, J., Sun, Y. \& Zhang, Y. (2011). The maturity empirical evaluation of real estate investment environment based on support vector machine. Proc. 2nd Int. Conf. on Artif. Intel., Manag. Sci. \& Electronic Commerce, Article number 6010263, pp. 800-803. https://doi.org/10.1109/AIMSEC.2011.6010263

44. González, M.A.S., Soibelman, L. \& Torres Formoso, C. (2005). A new approach to spatial analysis in CAMA. Property Management, 23(5), 312-327.

45. Bin, J., Tang, S., Liu, Y., Wang, G., Gardiner, B., Liu, Z. \& Li, E. (2017). Regression model for appraisal of real estate using recurrent neural network and boosting tree. Proc. of the 2nd IEEE Int. Conf. on Computational Intel. and Appl., pp. 209-213. https://doi.org/10.1109/CIAPP.2017.8167209

46. Yakubovskyi, V., Dimitrov, G.P., Bychkov, O. \& Panayotova, G. (2017). Combined neural network model for real estate market range value estimation. Proceedings of the 4th International Conference on Artificial Intelligence and Pattern Recognition, pp. 11-16.

47. Zhang, X. (2017). Optimization method of real estate estimation index system based on neural network algorithm. Technical Bulletin, 55(14), 664-670.

48. Abidoye, R.B. \& Chan, A.P.C. (2018). Achieving property valuation accuracy in developing countries: the implication of data source. International Journal of Housing Markets and Analysis, 11(3), 573-585. https://doi.org/10.1108/IJHMA-07-2017-0068

49. Yubin, Z. \& Bifang, L. (2009). Design and realization of FCE optimized model in DSS. Proc. of the WRI Global Congr. on Intel. Syst., 1, Art. no. 5208960, pp. 347-351.

50. Jin, Z. \& Yubin, Z. (2009). The design and application of enterprise comprehensive strength evaluation model based on artificial neural network. Proc. WRI Global Congr. on Intel. Syst., 1, Art. no. 5209054.

51. Qi, X., Qin, J., Zhao, L. \& Dai, Z. (2010). Design and application of monitoring system of Shenyang real estate market. Proc., 2nd Int. Conf. on Info. Sci. \& Engine., Article number 5690186, pp. 6505-6508.

52. $\mathrm{Xu}, \mathrm{H}$. \& Gade, A. (2017). Smart real estate assessments using structured deep neural networks. Proc. IEEE SmartWorld Ubiq. Intel. \& Comp., Adv. \& Trusted Comp., Scal. Comp. Comm., Cloud \& Big Data Comput. Internet of People \& Smart City Innov., pp. 1-7.

53. Kathmann, R.M. (1993). Neural networks for the mass appraisal of real estate. Computers, Environment and Urban Systems, 17(4), 373-384. https://doi.org/10.1016/0198-9715(93)90034-3

54. Antipov, E.A. \& Pokryshevskaya, E.B. (2012). Mass appraisal of residential apartments: An application of Random forest for valuation and a CART-based approach for model diagnostics. Expert Systems with Applications, 39(2), 1772-1778.

55. Ma, K., Zhang, Y. \& Yang, Z. (2018). Research on mass real estate evaluation mode based on BP neural 
network model. J. Advanced Comput. Intel. Intel. Infor., 22(7), 1099-1103.

56. Zhou, G., Ji, Y., Chen, X. \& Zhang, F. (2018). Artificial neural networks and the mass appraisal of real estate. Int. J. Online Engineering, 14(3), 180-187.

57. Zhang, X. \& Ji, W. (2010). Study on the risk assessment of real estate project based on BP neural network. Proceedings of the 2nd IEEE Int. Conf. on Info. \& Financial Engine., Article number 5609416, pp. 535-537.

58. Ju, Y.-J., Qiang, M. \& Qian, Z. (2009). A study on risk evaluation of real estate project based on BP neural networks. Int. Conf. on E-Business and Info. System Security, Article number 5137905.

https://doi.org/10.1109/EBISS.2009.5137905

59. Guo, W., Cao, M. \& Zheng, J. (2009). Study on Chinese banks of credit risk evaluation models of real-estate based on the BP-neural network model. WRI World Congr. on Comp. Sci. \& Info. Engine., 2, Article number 5171345, pp. 288-292.

60. Ma, Z.-Q. \& Meng, Q.-B. (2009). The research on risk evaluation of real estate development project based on RBF neural network. 2nd Int. Conf. on Info. \& Comput. Sci., 2, Article number 5169064, pp. 273-276.

61. Zhu, C., Zhan, Y. \& Jia, S. (2010). Research on BP neural network evaluation model of credit risk of bank clients. International Conference on Management and Service Science, Article number 5576862. https://doi.org/10.1109/ICMSS.2010.5576862

62. Huang, Y., Tian, C. \& Fang, W. (2009). Fuzzy comprehensive evaluation mode on the investment risk of real estate based on BP neural network and expert system. Int. Conf. on E-Business and Info. System Security, Article number 5137984.

63. Shi, H. (2012). Applying principal component analysis, genetic algorithm and support vector machine for risk forecasting of general contracting. $J$. Computers, 7(1), 301-307.

https://doi.org/10.4304/jcp.7.1.301-307

64. Zhao, Z., Luo, Z. \& Zhang, W. (2012). Real estate investment risk assessment based on GABP algorithm of neural network. International Journal of Digital Content Technology and its Applications, 6(3), 122-131.

65. Li, W. \& Shi, H. (2011). Applying unascertained theory, principal component analysis and ACO-based artificial neural networks for real estate price determination. Journal of Software, 6(9), 1672-1679. https://doi.org/10.4304/jsw.6.9.1672-1679

66. Li, X.G. \& Li, Q.M. (2006). The application of data mining technology in real estate market prediction. Proc. of CRIOCM Int. Research Symp. on Advancement of Constr. Manag. \& Real Estate, 2, 628-633.

67. Hu, X. \& Zhong, M. (2010). Applied research on real estate price prediction by the neural network. 2nd Conf. on Environ. Sci. \& Info. Appl. Tech., Article number 5567321, pp. 384-386.
68. Wanqing, L., Yong, Z., Wenqing, M. \& Shipeng, X. (2009). Study on the risk prediction of real estate investment whole process based on support vector machine. Proc. 2nd Int. Works. on Knowledge Discovery \& Data Mining, Art. no: 4771904, pp. 167-170.

69. El Hamzaoui, Y. \& Perez, J.A.H. (2011). Application of artificial neural networks to predict the selling price in the real estate valuation process. Proc. of the 10th Mexican Int. Conf. on Artif. Intel.: Adv. in Artificial Intel. \& Appl., Article number 6118994, pp. 175-181.

70. Diwan, S.A. (2019). Proposed study on evaluating and forecasting the resident property value based on specific determinants by case base reasoning and artificial neural network approach. Indo. J. Elect. Engine. Computer Sci., 17(3), 1467-1473.

71. Fang, R. (2017). Study on the optimization model of housing characteristic price based on the hedonic price interpretation model. Tech. Bull., 55(18), 43-49.

72. Zhang, P., Ma, W. \& Zhang, T. (2012). Application of artificial neural network to predict real estate investment in Qingdao. Lecture Notes in Electrical Engineering, 141, 213-219. https://doi.org/10.1007/978-3-642-27311-7_28

73. Lin, H.-Y. \& Chen, K. (2011). Predicting price of Taiwan real estates by neural networks and Support Vector Regression. Proc. of the 15th WSEAS Int. Conf. on Syst., pp. 220-225.

74. Nor, M.I., Masron, T.A. \& Gedi, S.Y. (2019). Modeling of residential property rents in Somalia using two-stage modeling: Hedonic regression and artificial neural network. International Journal of Housing Markets and Analysis, 10.1108/IJHMA-04-2019-0042.

75. Lin, H.-Y. \& Chen, K. (2011). Soft computing algorithms in Price of Taiwan Real Estates. WSEAS Transactions on Systems, 10(10), 342-351.

76. Liu, J., Zhang, X. \& Wu, W. (2005). Real estate price prediction model based on fuzzy neural networks. Proc. of the 11th Joint Int. Comput. Conf., pp. 592-595.

77. Zhao, L., Wang, L.-G. \& Qi, X.-J. (2014). Research of Shenyang real estate market based on generalized regression neural network. Journal of Northeastern University, 35(8), 1203-1205.

78. Dong, Y.-X., Xiao, Z. \& Xiao, X. (2014). Default prediction for real estate companies with imbalanced dataset. J. Info. Proces. Syst., 10(2), 314-333. https://doi.org/10.3745/JIPS.04.0002

79. Yang, L.-Y. \& Shao, C.-F. (2008). Integrated forecasting model for real estate price along urban rail transit based on BP neural network and Markov chain. Journal of Jilin University, 38(3), 514-519.

80. Zhong, Y., Zhou, C., Huang, L., Wang, Y. \& Yang, B. (2009). Support vector regression for prediction of housing values. CIS Int. Conf. on Computational Intel. \& Security, 2, Article number 5375753, pp. 61-65.

81. Shi, H. (2009). Determination of real estate price based on principal component analysis and artificial neural networks. 2nd Int. Conf. on Intel. Computing 
Tech. \& Automation, 1, Article number 5287649, pp. 314-317.

82. Sun, Z.H., Wang, J. \& Xu, B.J. (2013). The application of BP neural network learning algorithm based on the particle swarm optimization. Advanced Materials Research, 706-708, 2057-2062.

83. Shinde, N. \& Gawande, K. (2018). Survey on predicting property price. Int. Conf. on Automation \& Computational Engine., Art. no: 8687080, pp. 1-7.

84. Kiely, T.J. \& Bastian, N.D. (2019). The spatially conscious machine learning model. Statistical Analysis and Data Mining, 10.1002/sam.11440.

https://doi.org/10.1002/sam.11440

85. Shi, H. \& Li, W. (2009). Fusing neural networks, genetic algorithms and fuzzy logic for analysis of real estate price. Proc., Int. Conf. on Info. Engine. and Computer Sci., Article number 5362675.

86. Dongmei, H. (2010). Application research of rough-GA-BP method in the real estate early-warning system. Proc. Int. Conf. on Elect. \& Control Engine., Article number 5631570, pp. 483-485.

87. Li, Y., Zhang, H., Yang, F. \& Wang, Y. (2013). Applications of artificial neural networks in the identification of real estate cycles: Evidence from China. Proc. of the 18th Int. Symposium on Advance. of Constr. Manag. and Real Estate, pp. 185-195. https://doi.org/10.1007/978-3-642-44916-1_19

88. Oshodi, O.S., Thwala, W.D., Odubiyi, T.B., Abidoye, R.B. \& Aigbavboa, C.O. (2019). Using neural network model to estimate the rental price of residential properties. J. Fin. Manag. Prop. Const., 24(2), 217-230.

89. Zhang, S. (2012). Application of support vector machine in determination of real estate price. Advanced Materials Research, 461, 818-821.

90. Ke, K.-L. (2009). Default prediction of short-term loan based on integration of rough sets and support vector-machines. Control Theory and Applications, 26(12), 1365-1370.

91. Jian-Jiun, C., Kuentai, C. \& Ping-Yu, C. (2012). Pricing and analyzing the pre-owned house in Taipei City with Fuzzy variables. J. Quality, 19(4), 349-372.

92. Khobragade, A.N., Maheswari, N. \& Sivagami, M. (2018). Analyzing The Housing Rate In A Real Estate Informative System: A Prediction Analysis. Int. J. Civil Engine. Technol., 9(5), 1156-1164.

93. Poursaeed, O., Matera, T. \& Belongie, S. (2018). Vision-based real estate price estimation. Machine Vision and Applications, 29(4), 667-676.

94. Law, S., Paige, B. \& Russell, C. (2019). Take a look around: Using street view and satellite images to estimate house prices. ACM Transactions on Intelligent Systems and Technology, 10(5), Article number 54. https://doi.org/10.1145/3342240

95. Cao, Y., Nunoya, S., Suzuki, Y., Suzuki, M., Asada, Y. \& Takahashi, H. (2019). Classification of real estate images using transfer learning. Proc. Int. Soc. for Optical Engine., 11069, Article number 110691I. https://doi.org/10.1117/12.2524417

96. Baldominos, A., Blanco, I., Moreno, A.J., Iturrarte, R., Bernárdez, Ó. \& Afonso, C. (2018). Identifying real estate opportunities using machine learning. Applied Sciences, 8(11), Article number 2321 https://doi.org/10.1109/SIU.2017.7960205

97. Jasiński, T. (2018). Modelling of electricity demand in residential buildings using artificial neural networks. E3S Web of Conferences, 49, Article number 00048.

98. Solmaz, B., Yucesoy, V. \& Koc, A. (2017). Automated visual classification of indoor scenes and architectural styles. Proc. of the 25th Signal Processing and Commun. Appl. Conf., Article number 7960205.

99. Bappy, J.H., Barr, J.R., Srinivasan, N. \& RoyChowdhury, A.K. (2017). Real estate image classification. Proc. 17th IEEE Winter Conf. on Appl. of Computer Vision, Art. no: 7926631, pp. 373-381.

100.Popova, O., Simankina, T. \& Lukinov, V. (2016). Kohonen cards for clustering fund of the residential real-estate. MATEC Web of Conf., 106, Art. no. 01013.

101.Xue, D. \& Hao, S. (2012). Estimation of project costs based on fuzzy neural network. Proceedings of World Congress on Information and Communication Technologies, Article number 6409253, pp. 1177-1181.

102.Shi, H. \& Hou, W. (2011). Nonlinear analysis of core competence for real estate enterprise using evolutionary fuzzy neural inference model. Research J. Appl. Sci. Engine. Technol., 3(11), 1221-1226.

103.Shi, H. \& Deng, Y. (2010). Analysis on nonlinear core competence assessment model of real estate enterprise based on artificial neural network. Int. Conf. on Comp. Model. \& Simul., 2, Art. no. 5421099, pp. 179-182. https://doi.org/10.1109/ICCMS.2010.164

104.Wang, X.-Z. \& Xie, Q.-H. (2009). Wavelet neural network model application on the case selection of tax check in real estate industry. Int. Conf. on Intel. Human-Machine Syst. \& Cyber., 2, Art. no. 5336014, pp. 189-192.

105.Urbanavičiene, V., Kaklauskas, A., Zavadskas, E.K. \& Seniut, M. (2009). The web-based real estate multiple criteria negotiation decision support system: A new generation of decision support systems. Int. $J$. Strategic Property Manag., 13(3), 267-286.

106. Kontrimas, V. \& Verikas, A. (2007). Neural networks based screening of real estate transactions. Neural Network World, 17(1), 17-30.

107.Smith, M.H. \& Pedrycz, W. (1998). Designing dynamic temporally sensitive fuzzy neural networks. Annual Conference of the North American Fuzzy Information Processing Society, pp. 59-63. https://doi.org/10.1109/NAFIPS.1998.715530 